\title{
Sensitization to apomorphine, effects of dizocilpine NMDA receptor blockades
}

\author{
Martin J. Acerbo*, Jennifer M. Lee, Juan D. Delius \\ Allgemeine Psychologie, Universität Konstanz, 78457 Konstanz, Germany
}

\begin{abstract}
The dopamine agonist apomorphine (apo) elicits bouts of stereotyped pecking in pigeons, a response which increases with successive apo injections. This sensitization is strongly context-specific and has been suggested to arise through a Pavlovian conditioning to both external and internal cues. We hypothetized that this learning involves dopamino-glutamatergic interactions and investigated the issue by inducing NMDA glutamate receptor blockades with the antagonist dizocilpine (diz). A first experiment examined the effects that four different doses (ranging between 0.05 and $0.12 \mathrm{mg} / \mathrm{kg}$ ) of diz co-administered with a standard dose of $0.5 \mathrm{mg} / \mathrm{kg}$ of apo had on the development of the incremented response and on the later expression of the conditioned pecking response. Both responses were impaired by doses of around $0.10 \mathrm{mg} / \mathrm{kg} \mathrm{diz}$. A second experiment assessed whether either a diz treatment or a diz plus apo co-treatment affected the development of a subsequent sensitization to apo. The first treatment had no effect on the latter sensitization. A part sensitization that arose with the second treatment did not transfer to the final sensitization. The last experiment examined whether the administration of diz had an immediate effect on the incremented responding to apo and on the conditioned response shown by already sensitized pigeons. No effect was apparent with the first treatment, but there was a marked response inhibition with the second treatment. It is concluded that NMDA glutamate receptors play an important role in apo-induced sensitization in pigeons which is compatible with the Pavlovian conditioning account of sensitization.
\end{abstract}

Keywords: Dizocilpine; MK-801; Apomorphine; Sensitization; Conditioning; Glutamate; Dopamine; Pigeons; Pecking

\section{Introduction}

A behavioral response increment that occurs in rodents upon repeated administration of psychostimulant drugs such as amphetamine and cocaine is widely suspected to be connected with their addictive potency in humans [47]. The sensitization phenomenon appears to be linked with the activation of dopaminoreceptive mechanisms which these drugs are known to trigger [13,21,31,53,54]. Non-addictive, more specific, and more direct dopamine agonists than the two previously mentioned drugs, such as apomorphine (apo) and quinpirole are, however, also capable of producing a sensitization effect of comparable nature $[6,42,44,51,57]$. This may be due to the mes-telencephalic reward-signalling system of vertebrates which is well known to largely rely on dopaminergic transmission $[14,40,49]$. This fact may also be responsible for the finding that the sensitization to dopamine agonists in rodents is often at least partly

\footnotetext{
* Corresponding author. Present address: Department of Psychology, Biopsychology Program, University of Michigan, Ann Arbor, USA.

E-mail address: mjacerbo@umich.edu (M.J. Acerbo).
}

context-specific. It seems possible that this finding is due to a conditioning to the environmental cues that happen to be contingent with the drug experience $[4,8,11,16,38]$.

We have proposed that the behavioral sensitization which pigeons show in response to repeated administration of apo is largely, if not exclusively, due to a Pavlovian conditioning process. When a dose of about $0.5 \mathrm{mg} / \mathrm{kg}$ apo is administered for the first time to pigeons it occasions a bout of several hundred pecks that lasts somewhat less than $1 \mathrm{~h}$, an unconditioned response (UR). When the same dose is repeatedly injected, an incremented response (IR) develops and the pecking in the experimental cage increases to an asymptotic level of several thousand pecks produced within approximately $1.5 \mathrm{~h}[17,60]$. If later challenged with saline (sal) in the same cage, the pigeons exhibit a conditioned pecking response (CR) of about a hundred pecks within about $30 \mathrm{~min}$, a response that gradually extinguishes with sal-treatment repetitions $[12,28,39]$. Both the IR and the CR are markedly context-specific in the sense that they are only evident when the pigeons are exposed to the same experimental cage in which they were sensitized. If the pigeons are placed in a sufficiently different cage so as to avoid a simple stimulus 
generalization, the two responses are virtually absent. This is even so when the pigeons were pre-familiarized with the different cage while being sal-treated [3,34]. Furthermore, when thus-treated pigeons are later given the choice, their IR and CR pecking is nearly exclusively directed at visual features characteristic of the cage which they experienced while apo injected rather than at visual features typical of the cage which they experienced while sal was injected [33]. All this suggests that the cage in which the pigeons repeatedly experienced the effects of apo comes to act as a $\mathrm{CS}_{\text {cage } \times \text { apo }}$ to which a pecking CR develops. The fact that this CR seen in the relevant cage upon a sal challenge is of a markedly lesser magnitude than the IR obtained when the pigeons are challenged with apo in that same cage, is explained by the circumstance that the drug, besides acting as a US eliciting a UR, also induces an internal state that has demonstrable $\mathrm{CS}_{\text {apo }}$ properties $[19,20,30]$. The large IR that arises during the sensitization to apo is apparently driven by an approximately multiplicative stimulus compound $\mathrm{Cs}_{\text {cage } \times \text { apo }}$. The $\mathrm{CS}_{\text {apo }}$ component is naturally absent when a sal challenge in the $\mathrm{CS}_{\text {cage }}$ yields the weak pecking CR. A similarly weak, partial CR due to the $\mathrm{CS}_{\text {apo }}$ component alone can sometimes be obtained when the pigeons are apo-challenged in a cage different from that in which they were sensitized [33]. However, this response is often obscured by the strong, though somewhat variable, pecking UR directly elicited by the drug $[3,9,18]$.

Classical conditioning learning is commonly ascribed to a neurophysiogical long-term potentiation (LTP) processes known to occur in many glutamatergic synapses in vertebrates. The apo-induced conditioning that we hypothesize is likely to involve a dopamine-enhanced LTP variant [7,35]. The changes in synaptic efficacy underlying this variant are nevertheless attributed to a lasting increase in glutamatergic rather than dopaminergic synaptic transmission. The longer term modifications associated with LTP are thought to be principally due to an increase in AMPA receptor density in the post-synaptic membrane, an increase that can be facilitated by the co-activation of dopamine receptors [15]. In the present study we examine whether NMDA receptors actually play a role in the sensitization to apo shown by pigeons. If so, that would constitute further evidence that the sensitization is based on a conditioning process. The matter was examined by administering the NMDA receptor blocker dizocilpine (diz), also known as MK-801, during successive phases of the sensitization process. Diz binds in a non-competitive manner to the ionotropic NMDA receptors and near-permanently blocks their normal response to glutamate. This blockage, however, only affects already glutamate-activated, open channel receptors. In mammalian brain tissue diz reaches its maximum concentration some $30 \mathrm{~min}$ after it has been intramuscularly administered and persists there with a half-life of about $2 \mathrm{~h}$ [55]. The receptors blocked by diz are displaced to the periphery of the post-synaptic membrane and replaced within about $10 \mathrm{~min}$ by viable NMDA receptors $[48,52]$. The overall pool of vi- able NMDA receptors probably becomes exhausted when both glutamate and diz are present for some length of time. As diz vanishes, the pool is replenished by a slow unblocking of receptors and by a slow synthesis of new NMDA receptors, a process that may take some $18 \mathrm{~h}$ (G. Westbrook, personal communication). Apo, incidentally, is a potent, competitive agonist at D1- and D2-type dopamine receptors, acting within a few minutes after having been injected intramuscularly. It has a half-life of about $20 \mathrm{~min}$ in mammalian neural tissue [41,50].

The results of three experiments are reported. The first experiment dealt with the effects that four different doses of diz co-administered with the standard dose of apo had on the development of the IR and the subsequent expression of the CR. The second experiment assessed whether either a diz alone or a diz plus apo pretreatment affected the development of a subsequent sensitization IR to apo. The last experiment examined whether the administration of diz had an immediate effect on the expression of the IR and the CR in previously apo-sensitized pigeons.

\section{Methods}

\subsection{Subjects and procedures}

Drug naive adult pigeons (Columba livia), bred from local homing stock and weighing between 450 and $550 \mathrm{~g}$ were used. A week before the experiments began they were moved from an outside aviary to individual $40 \mathrm{~cm} \times 40 \mathrm{~cm} \times 45 \mathrm{~cm}$ stainless steel grid cages. These home cages were located in a well-ventilated and brightly lit ( $12 \mathrm{~h}$ on and $12 \mathrm{~h}$ off) room. Animal maintenance and treatments complied with the standards and rules specified by the German animal welfare law. It should be mentioned that at one point we discovered that we had accidentally used some pigeons that descended from inadvertently inbred pairs. These pairs had produced a high proportion of abnormally apo unresponsive offspring which were most probably homozygous for a recessive insensitivity mutant. The relevant birds $(n=5)$ were excluded and replaced by an equal number of identically treated, normally outbred pigeons.

The experimental cages used were modified standard cages. Their inner back- and side-wall surfaces were lined with white panels speckled with dark green dots $(0.8 \mathrm{~mm}$ in diameter, about $10 / 100 \mathrm{~cm}^{2}$ ). These distinctive cages were located in a separate, brightly lit room equipped with a video-camera and -recorder. Drug treatments were administered on a once-a-day schedule. After having received these treatments (see the following for details) the pigeons were immediately and individually placed into the distinctive cages and videotaped for $20 \mathrm{~min}$ before they were returned to their home cages. The videotapes were later reviewed and the numbers of pecks per session were counted with a tally-counter. The pecks of pigeons involve a quite distinct, easy to recognize motion pattern [29] and permit quite 
accurate counts that yield inter-observer agreement coefficients of $r_{\mathrm{s}}>0.85$. Nibbling and preening responses that sometimes occurred in lieu of pecking when the reaction to apo was partly suppressed by co-administered diz were disregarded. The experimental schedules to which the various groups of pigeons were subjected invariably consisted of two successive phases, mostly involving two different treatments. The abbreviated Xxx/Yyy-type names given to the groups allude to these sequential treatments. Daily mean scores and standard errors were calculated for each of the groups (see the following). Because the data were often not normally distributed, all statistical analyses were carried out with non-parametric Mann-Whitney $U$ (between-group comparisons) and Wilcoxon $T$ (within-group comparisons) tests.

\subsection{Drug treatments}

Apo obtained from Teclapharm as a ready clinical solution $(10 \mathrm{mg} / \mathrm{ml})$ was diluted with saline to a $1 \mathrm{mg} / \mathrm{ml}$ solution prior to injection. Throughout this study we used a standard $0.5 \mathrm{mg} / \mathrm{kg}$ dose of apo. In earlier studies it had been established that doses between 0.2 and $2 \mathrm{mg} / \mathrm{kg}$ apo yield an orderly increasing set of dose-dependent sensitization curves [5,27]. Dizocilpine(+)-maleate (MK-801), that is $(5 R, 10 S)-(+)-5$-methyl-10,11-dihydro-5H-debenzo[a,d] cyclohepten-5,10-imine, was obtained from Tocris Cookson and dissolved in sal to yield a $0.2 \mathrm{mg} / \mathrm{ml}$ solution. Preliminary trials showed that doses of more than $0.20 \mathrm{mg} / \mathrm{kg}$ had a strong sedating effect, often accompanied by some postural tottering, whereas doses of $0.12 \mathrm{mg} / \mathrm{kg}$ or less yielded at most a slight sedation. Furthermore, in a pilot experiment doses up to $0.12 \mathrm{mg} / \mathrm{kg}$ had no inhibitory effect whatsoever on the normal forage pecking of hungry pigeons. Based on these findings we began by employing doses ranging between 0.05 and $0.12 \mathrm{mg} / \mathrm{kg}$ diz. After diz injections the pigeons spent $30 \mathrm{~min}$ ( $20 \mathrm{~min}$ in one instance: see the following) in their home cages to allow for the drug-taking effect before the next treatment step. Equivolume doses of sal were administered for control purposes. All injections were given intramuscularly (pectoral muscles).

\subsection{Sensitization acquisition}

We first examined whether the co-administration of diz during the sensitization acquisition phase would interfere with the development of a pecking IR to apo and subsequently result in a diminished pecking CR in response to sal. Pigeons $(n=10)$ constituting an Apo/Sal baseline group were injected with apo and videotaped for 6 days and then injected with sal for another 3 days $(n=6)$ or 6 days $(n=4)$ and videotaped in the distinct cages. The pigeons of groups Diz5 + Apo/Sal $(n=5), \operatorname{Diz} 8+\operatorname{Apo} / \mathrm{Sal}(n=5)$, $\operatorname{Diz} 10+\operatorname{Apo} / \mathrm{Sal}(n=6)$, and Diz12+Apo/Sal $(n=5)$ were first injected with $0.05,0.08,0.10$, and $0.12 \mathrm{mg} / \mathrm{kg} \mathrm{diz}$, respectively, and returned to their home cages. Thirty minutes later all of these groups, which will sometimes be referred to as $\operatorname{Diz} X+\mathrm{Apo} / \mathrm{Sal}$ groups, were additionally injected with apo and videotaped. During the second phase all the pigeons of these groups were injected with sal and videotaped for 3 days except for the Apo-Diz10/Sal pigeons which were so treated for 6 days. Pigeons $(n=10)$ belonging to a Sal/Sal control group were injected with sal and videotaped for 9 days $(n=5)$ or 10 days $(n=5)$.

\subsection{Pretreatment effects}

It seemed possible that the second phase results obtained in the preceding experiment (see Section 3.2) might have been due to an after-effect of the diz treatments during the first phase. To check this, pigeons of a Diz/Apo group ( $n=$ 8) received $0.10 \mathrm{mg} / \mathrm{kg}$ diz injections and were videotaped $30 \mathrm{~min}$ later for 6 days. Pigeons of a Sal/Apo control group $(n=6)$ were pre-treated with sal injections instead of diz injections. An additional Diz + Apo/Apo group $(n=6)$ of pigeons was first administered $0.12 \mathrm{mg} / \mathrm{kg}$ diz and $20 \mathrm{~min}$ afterwards administered apo and then videotaped. The shorter than usual delay and the compensating higher dose used with this latter group was occasioned by a logistic constraint. During the second phase all the pigeons received apo only injections for a further 6 days, again being videotaped.

\subsection{Response retrieval}

In this experiment we examined whether diz would have an immediate effect on the expression the IR and the CR in pigeons that had previously been sensitized to apo. Pigeons belonging to an Apo/Diz+Apo group $(n=8)$, an Apo/Diz+ Sal group $(n=7)$, and an Apo/Apo control group ( $n=$ 6) were all injected with apo and videotaped for 6 days. During the second phase the Apo/Diz + Apo group received $0.10 \mathrm{mg} / \mathrm{kg} \mathrm{diz}$ and $30 \mathrm{~min}$ later the standard dose of apo for 4 days. The Apo/Diz + Sal group received $0.10 \mathrm{mg} / \mathrm{kg}$ diz before receiving sal for 3 days. The Apo/Apo group continued to receive apo as before for a further 4 days. After the sal or apo injections the pigeons were videotaped.

\section{Results}

\subsection{Sensitization acquisition}

During the first phase of the experiment the co-administration of all four doses of diz reduced the pecking induced by $0.5 \mathrm{mg} / \mathrm{kg}$ apo in an approximately dose-dependent manner. The lesser pecking of the Diz5 + Apo/Sal group compared with the Apo/Sal group, however, did not reach significance. All the other Diz + Apo/Sal groups exhibited significantly less pecking than the Apo/Sal group throughout days $1-6(P \mathrm{~s}<0.05)$. However, the pecking score differences between the Diz8 + Apo/Sal and Diz10 + Apo/Sal groups were not significant. Fig. 1 accordingly presents 


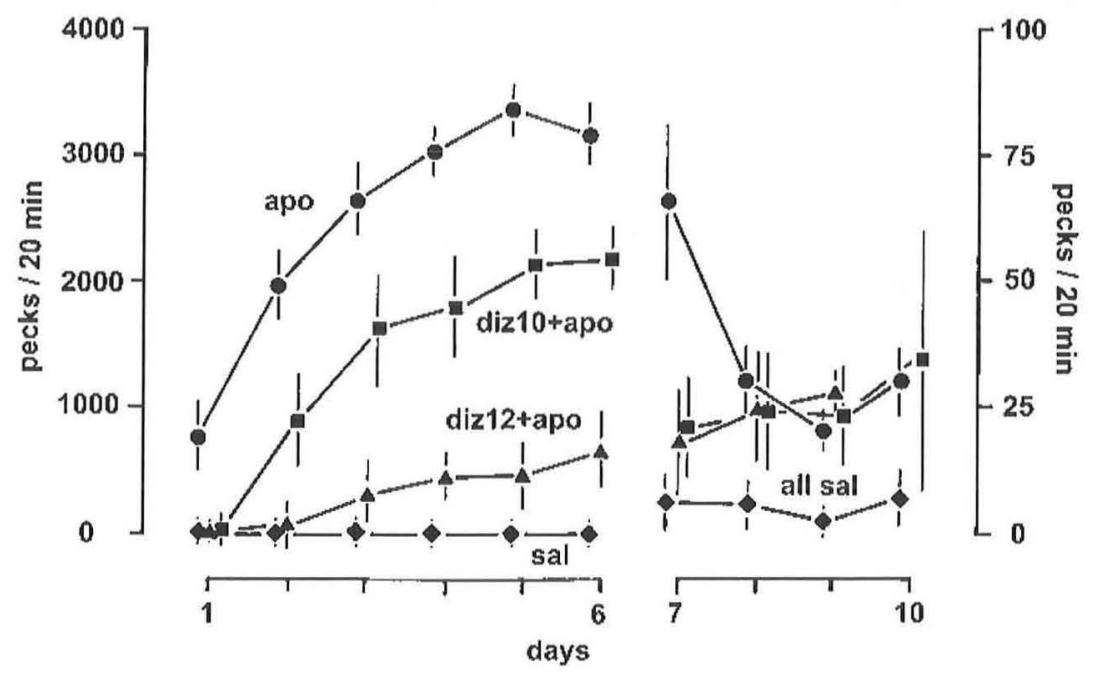

Fig. 1. Sensitization acquisition, mean pecking scores \pm S.E. Left: days 1-6 of Apo/Sal (O), Diz10 + Apo/Sal ( $\square$ ) and Diz12 + Apo/Sal ( $\mathbf{\Delta})$ groups while injected with $0,0.10$, or $0.12 \mathrm{mg} / \mathrm{kg}$ diz, respectively, and with apo. The Sal/Sal group ( ) was injected throughout with sal. Right: days $7-10$ while all groups were injected with sal. The Diz12 + Apo/Sal group was not tested on session 10 . Note that two differing response scales are valid for the right and left sections of the graph.

the results of only the Apo/Sal, Diz10 + Apo/Sal, and Diz12 + Apo/Sal groups. Of the latter two groups, the pecking scores pertaining to sessions $2-6$ and $4-6$, respectively, were nevertheless significantly higher $(P \mathrm{~s}<$ 0.05 ) than those of the Sal/Sal group, also shown in Fig. 1.

During the second phase of the experiment when all groups were treated with sal the Apo/Sal group yielded a sizeable pecking response during day 7 compared with the Sal/Sal group $(P<0.01)$, a response which, however, declined over the next two days. This decrease (extinction) from days 7 to 9 was significant $(P<0.01)$. All four $\operatorname{Diz} X+\mathrm{Apo} / \mathrm{Sal}$ groups yielded lesser pecking scores than the Apo/Sal group on day 7. This was significant in the case of the Diz8 + Apo/Sal, Diz10 + Apo/Sal, and Diz12 + Apo/Sal groups $\left(P_{\mathrm{S}}<0.05\right)$. The responding of all the $\operatorname{Diz} X+\mathrm{Apo} / \mathrm{Sal}$ groups tended to increase slightly after day 7 but not significantly so. In any case, the difference between their scores and those of the Apo/Sal group were no longer significant on day 8 and all subsequent days. However, from day 8 onwards the pecking scores of the Diz $X+$ Apo/Sal groups were all significantly higher than those of the Sal/Sal group $(P \mathrm{~s}<0.05)$. The co-administration of diz during the sensitization phase thus lead to a development of a diminished IR and later also to the expression of a reduced CR.

\subsection{Pretreatment effects}

Fig. 2 depicts the results of this experiment. As was expected both the Diz/Apo and the Sal/Apo pigeons pecked very little during the first phase. From day 3 onwards the Diz+Apo/Apo group pecked significantly more $(P \mathrm{~s}<0.01)$ than the formerly mentioned groups but significantly less
$(P \mathrm{~s}<0.05)$ than the Apo/Sal group of the previous experiment which is included in Fig. 2 for comparison. However, the present $\mathrm{Diz}+\mathrm{Apo} / \mathrm{Apo}$ group, although similarly treated with $0.12 \mathrm{mg} / \mathrm{kg} \mathrm{diz}$, pecked significantly more during days 3-6 ( $\left.P_{\mathrm{S}}<0.05\right)$, than the Diz12 + Apo/Sal group of Fig. 1 . The pecking of the said Diz + Apo/Apo group was in fact not significantly different from that of the Diz10 + Apo/Sal group shown in Fig. 1. This might have been because, as explained in Section 2.4, the interval between the diz and apo injections employed with the present Diz + Apo/Apo group was shorter than that normally used. During the second phase the Diz/Apo, Diz + Apo/Apo, and the Sal/Apo groups all exhibited statistically indistinguishable sensititization courses. They were slightly but not significantly lower than the sensitization courses evinced by the Apo/Sal group during the first phase (compare also with Fig. 3, left). This establishes that the diz treatments experienced by the Diz/Apo and Diz + Apo/Apo groups during the first phase did not affect the IR development during a subsequent sensitization to apo phase. Concerning the Diz/Apo group, the outcome agrees with the circumstance that the NMDA receptor blocking effect of diz persists for only $18 \mathrm{~h}$ (see Section 1). It is worth noting, however, that the partial IR that the $\mathrm{Diz}+\mathrm{Apo} / \mathrm{Apo}$ group had developed during the first phase did not transfer to the second phase (day 6 to day 7 drop, $P>0.01)$. A tentative explanation of this finding is offered later in the Section 4.

\subsection{Response expression}

The results of this experiment are shown in Fig. 3. During the first phase all the groups responded in a very similar manner. In fact, the sensitization courses of groups $\mathrm{Apo} / \mathrm{Diz}+\mathrm{Apo}$ and $\mathrm{Apo} / \mathrm{Diz}+\mathrm{Sal}$ were nearly identical and 


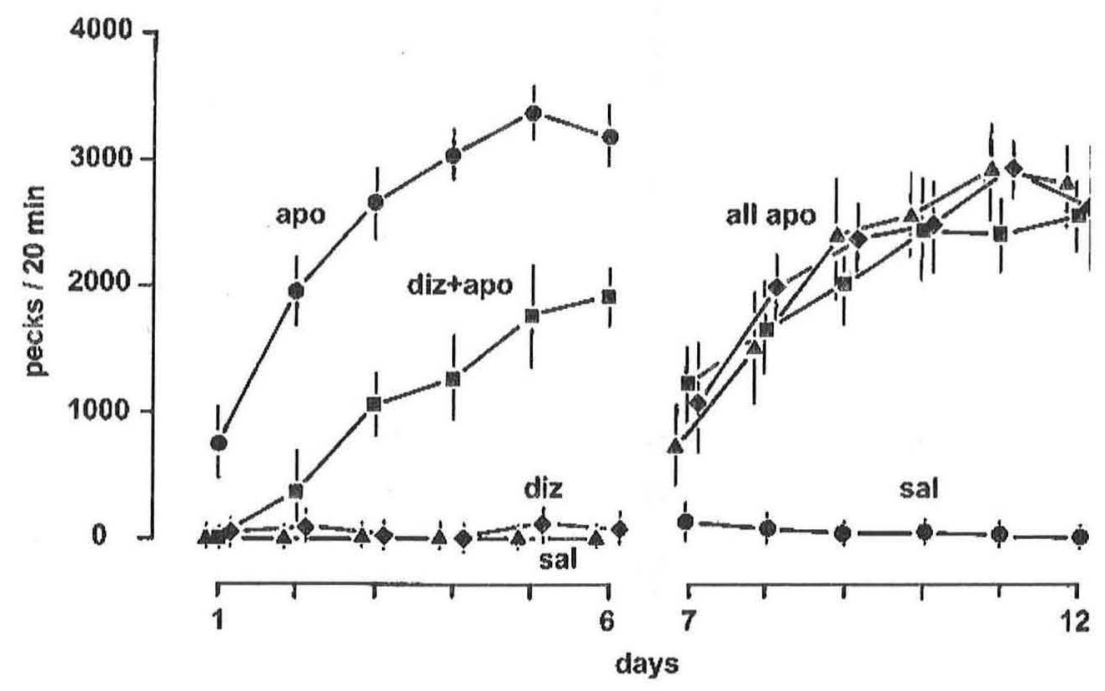

Fig. 2. Pretreatment effects, mean pecking scores \pm S.E. Left: days $1-6$ of groups Diz/Apo ( $)$, Sal/Apo (A), Diz + Apo/Apo ( while they were injected with diz, sal, diz and apo, or apo, respectively. Right: days 7-12, scores while the three first groups were injected with apo and the last one with sal. Note that here the same response scale is valid for both the right and the left sections of the graph.

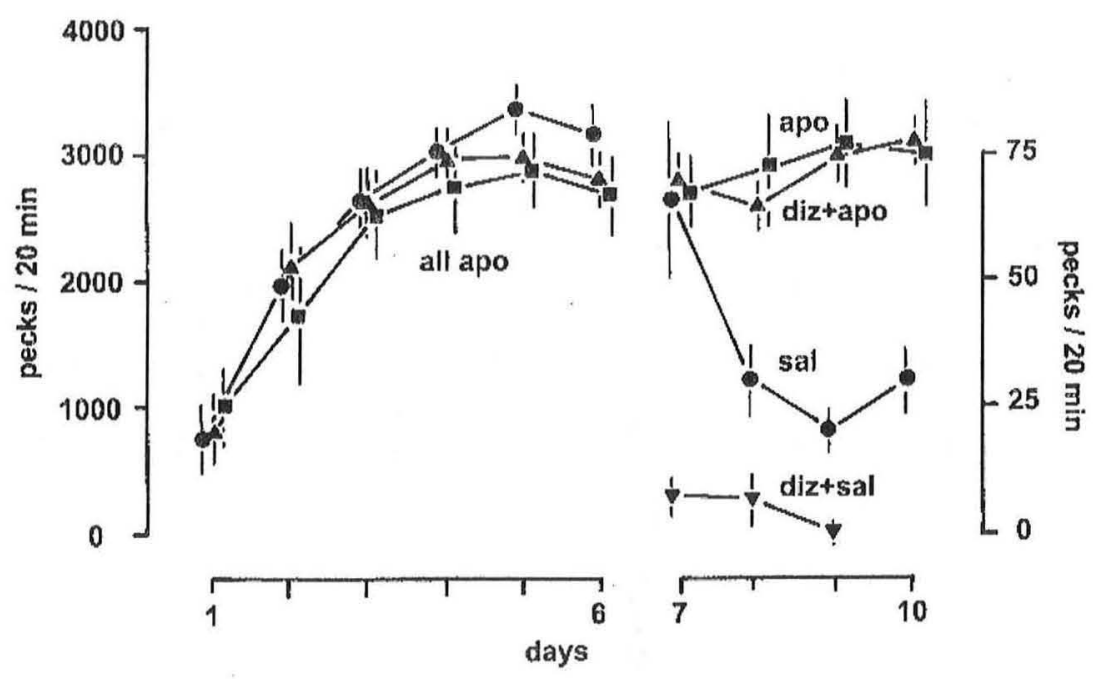

Fig. 3. Response expression. Mean pecking scores \pm S.E. Right: days $1-6$ of groups Apo/Apo $(\mathbf{D})$, Apo/Diz + Apo $(\mathbf{\Delta}, \mathbf{\Delta})$, Apo/Diz + Sal $(\boldsymbol{\Delta}, \boldsymbol{\nabla})$, and Apo/Sal (O) while all groups were treated with apo. The responses of groups Apo/Diz + Apo and Apo/Diz + Sal are shown pooled (see text). Right: days 7-10 of above groups while they were treated with apo, diz plus sal, diz plus apo, and sal, respectively. The Apo/Diz + Sal group was not tested on day 10. Note that an expanded scale is valid for the responses of the Apo/Sal and Apo/Diz + Sal groups during days 7-10.

are shown pooled for simplicity's sake. None of the sensitization courses differed significantly from that of the Apo/Sal group shown for comparison. The co-administration of $\mathrm{diz}$ which the Apo/Diz + Apo experienced during the second phase (days 7-10) did not affect the apo-sensitized pecking (compare with the Apo/Apo group). This indicates that once the IR is established, it can no longer be appreciably influenced by an NMDA receptor blockade. In contrast with that finding, the Apo/Diz + Sal group pecked very little during the second phase, significantly less in fact than the Apo/Sal group did during the same phase $(P s<0.05)$. A comparable diz treatment could thus suppress the expression of the weak CR but could not appreciably inhibit the much stronger IR.

\section{Discussion}

Several of the results reported above show that a first administration of a medium dose of apo in pigeons elicits a sizeable bout of stereotyped pecking (UR) and that a repeated treatment with the same dose of apo treatment yields a progressively increasing pecking response (IR). Furthermore, the Apo/Sal group (Fig. 1) demonstrates that, when challenged with sal, pigeons previously sensitized with apo exhibit a pecking CR. This confirms findings of several earlier studies in which it was additionally shown that the expression of both the IR and CR is strongly dependent on the pigeons being tested in the same distinctive cage in which they experienced the original sensitization treatment 
$[3,28,33,34]$. As explained in the Section 1 these and other studies $[12,39,60]$ have led us to postulate that the IR is the complete learned response shown when the full $\mathrm{CS}_{\text {cage xapo }}$ compound is present while the much weaker CR is only a part-response exhibited when the $\mathrm{CS}_{\text {cage }}$ component is present. A complementary part-response is elicited by the $\mathrm{CS}_{\text {apo }}$ component when the pigeons are treated with apo in a cage different from that in which they were previously sensitized. This small pecking response is difficult to ascertain because it is often obscured by variations of the much stronger UR directly elicited by apo through its unquestionable US quality [19,33]. Regardless of this, the sensitization to apo in pigeons is well accounted for by a Pavlovian conditioning process. In as much as this kind of learning appears to be neurally based on modifications of glutamatergic synapses and the onset of these modifications, in turn, are dependent on the activation of synaptic NMDA receptors, the co-administration of diz (MK-801), an NMDA receptor blocker, should have inhibitory effects on the development and expression of pecking IRs and CRs.

The role usually ascribed to the ionotropic NMDA receptors in LTP conditioning is that their channel opens when presynaptically released glutamate binds to them while the post-synaptic membrane is depolarized as a result of simultaneous activation of non-NMDA glutamate receptors. The inflow of calcium ions that follows triggers a complex biochemical cascade $[23,32]$. In dopamine-facilitated LTP, another such biochemical cascade may be triggered by dopamine D1 receptor activation $[35,46]$. When the two cascades converge they lead to the phosphorylation of a nuclear CREB protein [10]. When so activated this protein probably promotes the gene-controlled synthesis of AMPA glutamate receptors. These receptors are thought to play a critical role in the establishment of long-term memory [43]. In any case, viable NMDA receptors are assumed not to be any longer involved when the synaptic enhancement phase is over $[23,32])$. However, this latter view has been occasionally upset when NMDA receptor antagonists have been found to also impair the retrieval of previously well-learned responses (e.g. $[2,25,26])$. The synaptic mechanisms responsible for these model-anomalous findings are not yet properly understood.

The results pertaining to the various Diz $X+$ Apo/Sal groups (Fig. 1) indicate that a co-administration of a suitable dose of diz inhibits the acquisition of the IR and curtails the magnitude of the CR expressed afterwards. This accords with predictions that follow from the above LTP model. However, the very low day 1 pecking shown by the $\mathrm{Diz} 10+\mathrm{Apo} / \mathrm{Sal}$ and Diz12 + Apo/Sal groups (see also the $\mathrm{Diz}+$ Apo/Apo group, Fig. 2) suggests that the pecking UR elicited by apo is already inhibited by diz co-administration. This is an effect not foreseen by the LTP model. It may be that this dopaminergically triggered pecking response involves an intervening glutamatergic transmission link. The CR impairment, in any case, is unlikely to be due to any lingering diz since the Diz/Apo group (Fig. 2) did not re- veal any suppressive diz after-effect. But the reader should keep in mind that this latter remark does not invalidate the response strength and the diz state arguments forwarded in the following paragraphs.

As might be expected according to the standard LTP model, the second phase co-administration of diz and apo in the Apo/Diz + Apo group (Fig. 3) had no effect on the expression of the sensitization IR previously established through an apo-alone treatment. But in contrast to the standard model's predictions it was found with the Apo/Diz+Sal group (Fig. 3) that the administration of the same dose of diz inhibited the expression of a pecking CR in response to a sal challenge. It is possible that the difference in strength between the IR (more than 2000 pecks $/ 20 \mathrm{~min}$ ) and the CR (less than 100 pecks $/ 20 \mathrm{~min}$ ) is the source of the disparity. The diz administration, in agreement with the model-deviating findings mentioned earlier, might have impaired the retrieval of the weak CR but not have affected the much stronger IR.

The IR impairment observed in the Diz + Apo/Apo group (Fig. 2) during the first phase agrees, as already noted, with what was seen in the earlier discussed $\operatorname{Diz} X+$ Apo/Sal groups (Fig. 1). However, the fact that at the beginning of the second phase (day 7) the pecking response of the $\mathrm{Diz}+\mathrm{Apo} / \mathrm{Apo}$ group was not different from that of the previously unsensitized Diz/Apo and Sal/Apo groups (Fig. 2) is puzzling. This means that the part-sensitization that the Diz + Apo/Apo group had shown at the end of the first phase did not transfer to the second phase. An explanation may be that diz, besides partially blocking the sensitization during the first phase, was also acting as a component $\mathrm{CS}_{\mathrm{diz}}$ that made the part-sensitization to apo diz-state dependent (i.e. the controlling stimulus here was effectively a triple $\mathrm{CS}_{\text {cage } \times \text { apo } x \mathrm{diz}}$ compound). When the $\mathrm{CS}_{\mathrm{diz}} \mathrm{com}-$ ponent was left out during the second phase the previously acquired part-IR went missing and a new IR controlled by the simpler $\mathrm{CS}_{\text {cagexapo }}$ began to build up. In rodents it has been demonstrated that in drug discrimination experiments diz has a CS-like effect [37]. Nevertheless, this complication does not detract in the least from the replicated finding that diz co-administration interferes with the development of a pecking IR in response to repeated apo doses. The question whether this effect came about through inhibition of a $\mathrm{CS}_{\text {apo- }} \mathrm{IR}$, or of a $\mathrm{CS}_{\mathrm{cage}}$-IR linkage formation, or even both, can not be properly decided. By the way, we can also not totally discount the possibility that the reduced CRs shown by the $\operatorname{Diz} X+$ Apo/Sal groups (Fig. 1) might be also partly due to this hypothetical $\mathrm{CS}_{\mathrm{diz}}$ dropout effect.

\section{Conclusion}

We have shown that the development of the IR and the later expression of a CR that are characteristic of the pecking response sensitization arising with repeated apo administrations is impaired by NMDA receptor blockades brought about by a co-administration of diz. These findings were ex- 
pected on the basis that the sensitization to apo in pigeons depends on a dopamine-induced, LTP-like, classical conditioning process. But we also found that the retrieval of the CR elicited by the environmental context was similarly inhibited by diz blockades. This finding does not agree with the standard LTP model which assumes that the production of previously conditioned responses is independent of NMDA receptors. However, contrary to the theory, it is a frequent empirical finding that NMDA receptor antagonists can interfere with response retrieval. Our results in any case agree with the hypothesis that sensitization to apo in pigeons is based on a process leading to an alteration of glutamatergic transmission mechanisms. The results of two further studies involving the administration of dopamine D1 and D2 receptor antagonists in pigeons being sensitized or in pigeons already sensitized to apo $[1,3]$ agree with the above conclusion in as much as they indicated that the sensitization to apo does not entail a major change in dopaminergic transmission.

Although a large number of studies have investigated whether the sensitization in rodents to amphetamine and cocaine is affected by diz treatments, only a smaller number has examined how the sensitization to apo is affected by diz treatments. These studies have fairly consistently shown that the expression of a CR after an apo-sensitization is largely prevented when diz is administered before the challenge with sal $[6,22,24,56]$. Opinions about whether diz has an analogous effect on the emergence of the IR in response to apo are not so unanimous. One study found that a pre-administration of diz did not prevent the emergence of an apo-induced locomotory rotation IR in unilaterally substantia nigra lesioned rats [24]. Another study found that co-administration of diz immediately before apo did not impair and perhaps even enhanced a locomotor activity and stereotyped behavior IR in a context-dependent manner [56]. Nevertheless, several other studies report that the administration of $\mathrm{diz} 30 \mathrm{~min}$ before the injection of either apo or amphetamine prevented the development of a locomotor IR in rodents [6,22,24,36,45]. The discrepancies could of course be due to the differing strains, procedures, and drugs that were employed. A review adduces that although a co-administration of diz often inhibits the sensitization to amphetamine and cocaine in rodents, it can sometimes induce a sensitized locomotory response on its own which then adds to that produced by the psychostimulants $[58,59]$. Nevertheless, the author's overall conclusion is that NMDA receptors play a central role in the development of sensitization to amphetamine and cocaine. Even though we have some qualms about equating too easily the sensitization of psychostimulant-induced locomotor activity in rodents with the sensitization of apo-induced pecking behavior in pigeons it would seem that with respect to the involvement of NMDA receptors there are some interesting parallels. The avian apo-sensitization/conditioning preparation may in any case be a useful model for the study of the dopaminergic-glutamatergic synaptic interactions thought to underlie most sensory-motor learning in vertebrates.

\section{Acknowledgements}

The research was supported by grants from the Deutsche Forschungsgemeinschaft, Bonn. M.J.A. was the recipient of a Landesgraduierten Baden-Württemberg grant. We thank Ines Krug and Stephanie Iskra for technical assistance.

\section{References}

[1] Acerbo MJ, Delius JD. SCH-23390 blockade of behavioural sensitization due to apomorphine, submitted.

[2] Acerbo MJ, Gargiulo PA, Krug I, Delius JD. Behavioural consequences of nucleus accumbens dopaminergic stimulation and glutamatergic blocking in pigeons. Behav Brain Res 2002;136:171-7.

[3] Acerbo MJ, Godoy AM, Delius JD. Haloperidol blocks the acquisition, but not the retrieval of a conditioned response induced by apomorphine. Behav Pharmacol, in press.

[4] Anagnostaras SG, Schallert T, Robinson TE. Memory processes governing amphetamine-induced psychomotor sensitization. Neuropsychopharmacology 2002;26:703-15.

[5] Basten-Krefft A. Apomorphin-induziertes Verhalten bei Tauben (Apomorphine-induced behaviour in pigeons). Diplomthesis. Bochum, Ruhr-University, Germany; 1977.

[6] Battisti JJ, Uretsky NJ, Wallace LJ. Importance of environmental context in the development of amphetamine- or apomorphine-induced stereotyped behavior after single and multiple doses. Pharmacol Biochem Behav 2000;66:671-7.

[7] Bell K, Duffy P, Kalivas PW. Context-specific enhancement of glutamate transmission by cocaine. Neuropsychopharmacology 2000;23:335-44.

[8] Bonate PL, Swann A, Silverman PB. Context-dependent crosssensitization between cocaine and amphetamine. Life Sci 1997;60: PL1-7.

[9] Bouton ME. Context, time, and memory retrieval in the interference paradigms of Pavlovian learning. Psychol Bull 1993;114:80-99.

[10] Brami-Cherrie K, Valjent E, Garcia M, Pagès C, Hipskind RA, Caboche J. Dopamine induces a PI3-kinase-independent activation of Akt in striatal neurons: a new route to cAMP response elementbinding protein phosphorylation. J Neurosci 2002;22:8911-21.

[11] Browman KE, Badiani A, Robinson TE. The influence of environment on the induction of sensitization to the psychomotor activating effects of intravenous cocaine in rats is dose-dependent. Psychopharmacology 1998;137:90-8.

[12] Burg B, Hasse C, Lindenblatt U, Delius JD. Sensitization to and conditioning with apomorphine in pigeons. Pharmacol Biochem Behav 1989;34:59-64.

[13] Cador M, Bjijou Y, Stinus L. Evidence of a complete independence of the neurobiological substrates for the induction and expression of behavioral sensitization to amphetamine. Neuroscience 1995;65:38595.

[14] Cador M, Taylor JR, Robbins TW. Potentiation of the effects of reward-related stimuli by dopaminergic-dependent mechanisms in the nucleus accumbens. Psychopharmacology 1991;104:377-85.

[15] Centonze D, Picconi B, Gubellini P, Bernardi G, Calabresi P. Dopaminergic control of synaptic plasticity in the dorsal striatum. Eur J Neurosci 2001;13:1071-7

[16] Crombag HS, Badiani A, Maren S, Robinson TE. The role of contextual versus drug-associated cues in promoting the induction of psychomotor sensitization to intravenous amphetamine. Behav Brain Res 2000; 116:1-22.

[17] Delius JD. The pecking of the pigeon: free for all. In: Lowe CF, Richelle M, Blackman DE, Bradshaw, CM, editors. Behavior analysis and contemporary psychology. New York: Erlbaum; 1985. p. 53-81. 
[18] Delius JD, Acerbo MJ, Keller S, Godoy AM. Drogeninduziertes Lernen: Sensitivierung bei Apomorphin (Drug-induced learning: sensitization to apomorphine). Neuroforum 2002;4:261-6.

[19] Delius JD, Krug I, Acerbo M, Keller S, Leydel R. Sensitization to apomorphine, a multifaceted process, in preparation.

[20] Djamoz MB, Wagmer HJ. Localization and function of dopamine in the adult vertebrate retina. Neurochem Int 1992;20:139-91.

[21] Druhan JP, Jakob A, Stewart J. The development of behavioral sensitization to apomorphine is blocked by MK-801. Eur J Pharmacol 1993;243:73-7.

[22] Druhan JP, Wilent WB. Effects of the competitive $N$-methyl-Daspartate receptor antagonist CPP on the development and expression of conditioned hyperactivity and sensitization induced by cocaine. Behav Brain Res 1999;102:195-210.

[23] Fazeli MS, Collingridge GL. Cortical plasticity: LTP and LTD. Oxford: Bios; 1996

[24] Gancher S, Mayer A. Sensitization to apomorphine-induced rotational behavior in 6-OHDA-lesioned rats: effects of NMDA antagonists on drug response. Brain Res 1995;682:63-8.

[25] Gargiulo PA, Siemann M, Delius JD. Visual discrimination in pigeons impaired by glutamatergic blockade of nucleus accumbens. Physiol Behav 1998;63:705-9.

[26] Gargiulo PA, Acerbo, MJ, Krug I, Delius JD. Cognitive effects of dopaminergic and glutamatergic nucleus accumbens blockades in pigeons, submitted.

[27] Godoy AM. Dopamine and learning in the pigeon (Columba livia). Doctoral thesis. Konstanz, Germany: University of Konstanz; 2000.

[28] Godoy A, Delius JD. Sensitization to apomorphine in pigeons due to conditioning, subject to generalisation but resistant to extinction. Behav Pharmacol 1999;10:367-78.

[29] Hörster W, Krumm E, Mohr C, Delius JD. Conditioning the pecking motions of pigeons. Behav Proc 2002;58:27-43.

[30] Jarbe TU. Discriminative stimulus properties of cocaine: effects of apomorphine, haloperidol, procaine and other drugs. Neuropharmacology 1984;23:899-907.

[31] Kalivas PW, Pierce RC, Cornish J, Sorg BA. A role for sensitization in craving and relapse in cocaine addiction. J Psychopharmacol 1998;12:49-53.

[32] Kandel ER. Cellular mechanisms of learning and the biological basis of individuality. In: Kandel ER, Schwartz JH, Jessell TM editors. Principles of neural science. New York: McGraw-Hill; 2001.p. 1247-79.

[33] Keller S, Delius JD, Acerbo MJ. Apomorphine sensitization: evoking conditions, context dependence, effect persistence and conditioned nature. Behav Pharmacol 2002;13:189-201.

[34] Keller S, Delius JD. Discriminative learning occasioned by the administration of a dopamine agonist. Psychopharmacology 2001;57:3203.

[35] Kelley AE. Neural integrative activities of nucleus accumbens subregions in relation to learning and motivation. Psychobiology 1999;27:198-213.

[36] Kim HS, Jang CG. MK-801 inhibits methamphetamine-induced conditioned place preference and behavioral sensitization to apomorphine in mice. Brain Res Bull 1997;44:221-7.

[37] Koek W. NMDA antagonists and drug discrimination. Pharmacol Biochem Behav 1999;64:261-75.

[38] Lienau AK, Kuschinsky K. Sensitization phenomena after repeated administration of cocaine or $\mathrm{D}$-amphetamine in rats: associative and non-associative mechanisms and the role of dopamine in the striatum. Naunyn Schmied Arch Pharmacol 1997;355:531-7.

[39] Lindenblatt U, Delius JD. Apomorphine-induced pecking in pigeons classically conditioned to environmental cues. Psychopharmacology 1987;93:223-5.
[40] Martel P, Fantino M. Mesolimbic dopaminergic system activity as a function of food reward: a microdialysis study. Pharmacol Biochem Behav 1996;53:221-6.

[41] Martres MP, Costentin J, Baudry M, Marcais H, Protais P, Schwartz JC. Long-term changes in the sensitivity of pre-and postsynaptic dopamine receptors in mouse striatum evidenced by behavioural and biochemical studies. Brain Res 1977;136:319-37.

[42] Mattingly BA, Koch C, Osborne FH, Gotsick JE. Stimulus and response factors affecting the development of behavioral sensitization to apomorphine. Psychopharmacology 1997;130:109-16.

[43] Mayfor M, Kandel ER. Genetic approaches to memory storage. Trends Genet 1999;15:463-70.

[44] Muscat R, Iravani MM, Kruk KL. The role of ventral tegmental dopamine in locomotor sensitization following quinpirole or (+)amphetamine: ex vivo voltammetric evidence. Neuroscience 1996; 75:1175-84.

[45] Nomikos GG, Mathé AA, Mathé JM, Svensson TH. MK-801 prevents the enhanced behavioural response to apomorphine elicited by repeated electroconvulsive treatment in mice. Psychopharmacology 1992;108:367-70.

[46] Olds ME. Dopaminergic basis for the facilitation of brain stimulation reward by the NMDA receptor antagonist, MK-801. Eur J Pharmaco 1996;306:23-32.

[47] Robinson TE, Berridge KC. Addiction. Ann Rev Psychol 2002;54:25-53

[48] Rosenmund C, Clements JD, Westbrook GL. Non-uniform probability of glutamate release at a hippocampal synapse. Science 1993;263:754-7.

[49] Schultz W. Dopamine neurons and their role in reward mechanisms. Curr Opinion Neurobiol 1997;7:191-7.

[50] Smith RV, Wilcox RE, Soine WH, Riffee WH, Baldessarini RJ, Kula NS. Plasma levels of apomorphine following intravenous, intraperitoneal and oral administration to mice and rats. Res Comm Chem Pathol Pharmacol 1979;24:483-99.

[51] Tirelli E, Heidbreder C. Conditioning of and contextual sensitization to apomorphine-induced climbing in mice: evidence against the habituation hypothesis. Behav Neurosci 1999;113:368-76.

[52] Tovar KR, Westbrook GL. Mobile NMDA receptors at hippocampal synapses. Neuron 2002;34:255-64.

[53] Vezina P. D1 dopamine receptor activation is necessary for induction of sensitization by amphetamine in the ventral tegmental area. J Neurosci 1996;16:2411-20.

[54] Vezina P, Stewart J. Amphetamine administrated to the ventral tegmental area but not to nucleus accumbens sensitizes rats to systemic morphine: lack of conditioned effects. Brain Res 1990;516:99106.

[55] Vezzani A, Serafini R, Stast MA, Coccia S, Conti I, Tridic RV, Samanin R. Kinetics of MK-801 and its effect on quinolinic acidinduced seizures and neurotoxicity in rats. J Pharmacol Exp Ther 1989;249:278-83.

[56] Welsch-Kunze S, Kuschinsky K. On the possible involvement of glutamate receptors in conditioning of behavioural effects of apomorphine. Psychopharmacology 1990;101:421-8.

[57] Willner P, Papp P, Cheeta S, Muscat R. Environmental influences on behavioural sensitization to the dopamine agonist quinpirole. Behav Pharmacol 1992;3:43-50.

[58] Wolf ME. The role of excitatory amino acids in behavioral sensitization to psychomotor stimulants. Prog Neurobiol 1998;54:679-720.

[59] Wolf ME. NMDA receptors and behavioural sensitization; beyond dizocilipine. Trends Pharmacol Sci 1999;20:188-9.

[60] Wynne B, Delius JD. Sensitization to apomorphine in pigeons: unaffected by latent inhibition latent inhibition but still due to classical conditioning. Psychopharmcology 1995;119:414-20. 